\section{Re-wilding: no need for exotics as natives return}

SIR — In their Commentary ${ }^{\alpha} \mathrm{Re}$-wilding North America" (Nature 436, 913-914; 2005), Josh Donlan and colleagues propose introducing Asian and African species to the Great Plains. But they do not discuss a real effort that is already under way to restore native North American prairie wildlife on the Northern Great Plains.

The World Wildlife Fund and its partner, the American Prairie Foundation, have launched an ambitious programme to purchase, from willing sellers, property in north-central Montana. When combined with adjacent public lands, this would provide the habitat for nearly the entire suite of North American grassland species that have lived here within the past 10,000 years.

These efforts envisage reintroducing bison from remaining genetically pure herds and providing habitat that will support increasing populations of nearly extinct species such as black-footed ferrets. If all goes well, there will be an increase in populations of pronghorns, elks, mountain plovers, burrowing owls and large predators such as mountain lions - our native felid, which has already recolonized this area without human intervention. At least parts of the megafauna-dominated landscape can be restored in a few decades, and Pleistocene survivors such as bison will once again be able to play their role as ecological engineers.

This restoration of native prairie wildlife is being carried out in cooperation with local landowners and communities. It addresses concerns about the return of prairie species that, in some cases, have been absent for a century or more. Restoring the native fauna of this region first is a more economically viable and ecologically sound approach, if the goal is to energize positive support for conservation in general.

Eric Dinerstein ${ }^{\star}$, W. Robert Irvin $\dagger$

*Conservation Science, Warld Wildlife Fund, †USEcoregional Conservation, World Wildlife Fund, 1250 Twenty-Fourth Street, NW, Washington DC 20036, USA

\section{Re-wilding: don't overlook humans living on the plains}

SIR — Proposals made by Josh Donlan and colleagues to "re-wild" the Great Plains ( ${ }^{\circ}$ Re-wilding North America ${ }^{\prime}$ Nature 436, $913-914 ; 2005$ ) assume that if the land is void of people, it is necessarily open to exotic megafauna. As a historian of the twentiethcentury American West, I disagree, and I believe the re-wilding plan would be harmful to current environmental efforts in the area.

The human population may be sparse, but people on the plains use large areas of land to drive the economies of the towns that dot the landscape. In the late 1980 s, a group of well-meaning people tried to gather support for the Big Open project. This was part of a larger proposal, called the Buffalo Commons, to establish a huge preserve for bison covering 139,000 square miles in ten states from Texas to Montana. Local people overwhelmingly rejected the proposal. Subsequent anti-environmentalist and anti-government feeling damaged efforts that were being made towards environmental sustainability.

But local alliances can be productive, and the stubborn search for middle ground has led to some recent victories for biodiversity in the region. Bison have been reintroduced to Native American reservation lands, land has been restored by Nature Conservancy, plans are in progress to pay ranchers to reduce the number of cattle grazing, and coal bed methane pollution has been opposed by the Northern Plains Resource Council. Some ranchers have taken up environmentally friendlier practices, such as adjusting cattle grazing on the Plains, by use of fencing, to mimic the habits of bison: intensive grazing for a shorter period of time.

Politicians, ranchers and academics have started talking to each other constructively. Can we honestly now ask the region to ingest lions and cheetahs?

Steven Shay

Department of History, Washington State University, Pullman, Washington 99164, USA

\section{How synthetic biology can avoid GMO-style conflicts}

SIR - Your News story ${ }^{\alpha}$ Synthetic biologists face up to security issues" (Nature 436, $894-895 ; 2005$ ), defines synthetic biology as the ability "to create complete genomes from scratch and to introduce new characteristics into viruses and bacteria ${ }^{x}$. But the second half of this definition has already been applied for decades to genetically modified organisms (GMOs), and particularly to modified viral genomes. The present discussion about regulation of synthetic biology should carefully consider how and why GMOs are regulated, in order to avoid regulatory chaos.

The US and Canadian systems for GMO regulation are based on the properties of the organisms produced, whereas the European system is based more on techniques. The incompatibility between product-based and technique-based systems is the source of much of the transatlantic tension regarding GMOs.

North American scientists are calling for technique-based regulation of synthetic biology. But for products of synthetic biology that bear novel genes and thus are also GMOs, which type of regulation should prevail: technique- or product-based? If the former, one would quickly encounter the situation where equivalent organisms, synthetic or classic GM, would be regulated using drastically different strategies and criteria. If the latter, the most potentially dangerous products of synthetic biology would simply be regulated as GMOs. If the United States and/or Canada go forward with techniquebased regulation of synthetic biology, a minimum of coherence would require them also to shift to technique-based regulation of GMOs - a major policy change.

I believe that the first step to reassure the public about synthetic biology should be to cool the rhetoric. The present situation is reminiscent of 30 years ago, when some of the pioneers in the then-new field of genetic engineering made unrealistic claims about what was feasible; this was one of the major early sources of public uneasiness about GMOs. There should be a bit more modesty in claims both about what can be achieved by synthetic biology in the foreseeable future, and about what could be achieved by additional regulatory supervision.

Mark Tepfer

ICGEB Biosafety Outstation, Via Piovega 23, 31056 Ca' Tron di Roncade, Italy

\section{Chiropractors start major study of spinal outcomes}

SIR - Your News story "Survey questions safety of alternative medicine" (Nature 436, 898 ; 2005) quotes Edzard Ernst as saying that complementary and alternative medicine (CAM) organizations are not doing enough to monitor adverse reactions. It also reports that chiropractic treatments sometimes have serious side-effects.

The British Chiropractic Association (BCA) is currently undertaking a large-scale observational study (sample size of over $50,000)$ to document patient outcomes after cervical spine manipulation. Final data analysis is expected in 2006, and we hope to publish the results in peer-reviewed journals.

The BCA has also, in conjunction with the Anglo-European Chiropractic College, set up a chiropractic reporting and learning system; more than 1,200 practitioners who are members of the BCA have recently received an information pack to enable them to participate in the scheme. Resulting data will be analysed at the Anglo-European Chiropractic College and outcomes will be relayed to the profession, through our newsletter, journal and website, so practitioners may learn from the experience of others.

The intention is that the scheme will, if successful, be offered to other chiropractic associations within Europe in 2006.

Barry Lewis

BritishChiropractic Association, Blagrave House, 17 Blagrave Street, Reading RG1 1QB, UK 